\title{
BMJ Open Quality All change: a stroke inpatient service's experience of a new clinical neuropsychology delivery model
}

\author{
Ndidi T Boakye, ${ }^{1}$ Richard Scott, ${ }^{1}$ Aisling Parsons, ${ }^{1}$ Shai Betteridge, ${ }^{1}$ \\ Melody A Smith, ${ }^{1}$ Gill Cluckie $^{2}$
}

To cite: Boakye NT, Scott $R$, Parsons A, et al. All change: a stroke inpatient service's experience of a new clinical neuropsychology delivery model. BMJ Open Quality 2019;8:e000184. doi:10.1136/ bmjoq-2017-000184

Received 11 August 2017 Revised 16 November 2018 Accepted 21 November 2018
Check for updates

(c) Author(s) (or their employer(s)) 2019. Re-use permitted under CC BY-NC. No commercial re-use. See rights and permissions. Published by BMJ.

${ }^{1}$ Department of

Neuropsychology and Clinical Health, St George's University Hospitals, London, UK

${ }^{2}$ Stroke Service, Department of Neurosciences, St George's University Hospitals, London, UK

Correspondence to

Dr Ndidi T Boakye;

drndidiboakye@gmail.com

\section{ABSTRACT}

Adults presenting to stroke services are frequently faced with the challenge of adjusting to a different life following a stroke. Difficulties often include cognitive impairments, such as memory deficits, attention and language difficulties, and mood disturbances such as anxiety and depression. It has been highlighted that psychological care for this group is just as important as physical rehabilitation. Psychological expertise may therefore be required for the multitude of problems that occur after a stroke. UK National guidelines recommend routine assessment and management of mood and cognition after stroke. The aim of this study was to evaluate a new stroke clinical neuropsychology service developed by the Department of Neuropsychology and Clinical Health Psychology, in order to meet the needs of stroke survivors and their families referred into a large acute hospital. This involved using a different skill mix of staff across one post delivering a service in an acute inpatient stroke unit. This model was evaluated and results revealed that the model delivered increased patient access to neuropsychological support, an expansion in provision of clinical work, along with positive multidisciplinary team feedback. This finding is key as where resources are limited, clinical services may benefit from adopting a 'skill mix' model to meet the varying needs of their patients in a timely manner. This model serves to raise the value of psychology to medical services.

\section{PROBLEM}

It is estimated that depression occurs in almost one-third of stroke survivors. ${ }^{1}$ It is also associated with higher rates of mortality. ${ }^{2}$ Other psychological problems such as difficulty with adjustment to life following stroke are also common. Furthermore, anxiety, strain and other psychological problems are frequently reported in carers of people with stroke. ${ }^{34}$

Psychological expertise may therefore be required for the multitude of problems that occur after a stroke. The National Institute for Health and Care Excellence (NICE) and the Royal College of Physicians (RCP) recommend routine assessment and management of mood and cognition after stroke. ${ }^{15}$ For example, neuropsychological assessment can be helpful in identifying hidden, complex and high-level impairment. ${ }^{6}$ Furthermore, regular mood monitoring and subsequent provision of specialised intervention will be required by most stroke survivors. ${ }^{5}$ Research suggests that psychological interventions show greater effectiveness in managing symptoms of depression after stroke compared with antidepressants. ${ }^{7}$ However, the psychology provision for stroke services varies across the UK and accessibility is largely dependent on where patients live. Care of patients' physical needs may sometimes take priority and staff may have little time or not be adequately trained to deal with psychological issues presented by their patients. ${ }^{6}$ As a result, the RCP guidelines for recommended psychology staffing levels for stroke units is 0.20 whole time equivalent (WTE) per five beds. However, it can prove challenging to find such a resource nationally.

\section{BACKGROUND}

Stroke occurs approximately 152000 times a year in the UK, affecting approximately 150000 people. $^{8}$ It is the third most common cause of death, following heart disease and cancer and a significant cause of disability. ${ }^{9}$ Recent data suggests that 450000 people in the UK are currently severely disabled as a result of stroke. ${ }^{9}$

It has long been recognised that effective stroke treatment requires a multidisciplinary team (MDT) approach and early multidisciplinary assessment and treatment has been recommended. ${ }^{510}$ This includes occupational therapists, physiotherapists, speech and language therapists, clinical psychologists, dieticians, pharmacists and stroke physicians.

Stroke survivors experience several services as part of their treatment pathway such as accident and emergency, rehabilitation and community health teams. It is therefore not uncommon for psychological problems to occur at any of these stages. National Health Service (NHS) Improvement Stroke highlights that psychological care for this group 
was just as important as physical rehabilitation. ${ }^{11}$ This is crucial as people with stroke and their families go on to manage the impact of stroke on their lives in the longer term. More importantly, up to $80 \%$ of people with stroke will have significant cognitive impairment such as memory impairment, attention, language and perceptual difficulties. $^{12} 13$ Other needs identified include reactions to disability and dependency, poststroke fatigue, adjustment difficulties and challenging behaviour and return to work. ${ }^{6}$ Mood disturbances such as depression and/or anxiety are also quite common. Consequently, clinical psychologists working in stroke services will often find themselves providing a variety of different services such as general mood assessment, consultation, neuropsychological testing, family work and brief interventions. However, to date only one-third of stroke units have access to clinical psychology services and when psychologists are present the WTE per bed is low. ${ }^{5}$ This can lead to psychological aspects of care being reported as the most problematic. ${ }^{6}$ Clinicians working in services where the clinical demand for psychological provision is high, find themselves dedicating time to teaching and training colleagues who may often be in the position of delivering lower level psychological interventions. ${ }^{6}$ There is therefore a growing need for psychologists to be creative and flexible in developing of services in order to meet the demands of provision for an ever-increasing ageing population.

\section{DESIGN}

Prior to a review of the Stroke Clinical Neuropsychology service in 2015 by the Head of Neuropsychology and Lead Psychologist for the Stroke pathway, the service provision was provided by 1.0 WTE Band 8a Clinical Psychologist. The 2015 review recommended the service be redesigned to increase access to psychology (ie, number of patients seen and variety of interventions) in line with RCP guidance and enhance MDT working. A redesign would also need to address service and MDT concerns about the lack of psychology input when the psychologist was absent due to sickness or leave (minimum 28 days per year entitlement). The review concluded that a 'skill-mix' model of psychology staffing would provide the most effective way of identifying need and enabling the delivery of a variety of psychological interventions to a 20 bed Hyper-Acute and a 16 bed Acute Stroke service at a large national hospital. The plan was to implement the skill-mix model to improve access to psychology and improve MDT working.

The new Stroke Clinical Neuropsychology service 'skill mix' model consisted of 0.4 WTE Band 8b Clinical Neuropsychologist, who provided strategic oversight such as management, highly specialist assessment, intervention and supervision across the stroke service; 0.6 WTE Band 7 Clinical Psychologist who delivered specialist psychological assessment and interventions (eg, cognitive behavioural therapy, cognitive rehabilitation) in collaboration with the MDT; 0.2 WTE Band 4 Assistant
Psychologist, who provided low-intensity interventions such as mood screening and behavioural activation. The model was also supported by Trainee Clinical Psychologists on placement who provided a low to high intensity psychological assessments and interventions and/or Honorary Assistant Psychologists who provided low intensity interventions. The skill-mix model provided assessment and interventions to patients with a spectrum of needs and continuity of psychology care as recommended by the RCP. This was possible as resources were available and clinicians were matched to patients based on needs. Also embedded into the model, were daily ward rounds, carried out by the Band 7 and or the Band 4 psychologists, a database containing handover information and a daily email circulation containing pertinent information, which aided communication across the stroke psychology team. The service as described above is a new 'skill mix' model of provision and was implemented at one time in February 2015, following consultation with senior staff members in the Stroke service.

\section{STRATEGY}

Prior to February 2015, the Stroke Clinical Neuropsychology service operated a referral system for patients on both the Hyper-Acute Stroke Unit (HASU) and Acute Stroke Unit (ASU). However, since the introduction of the skill mix model, all patients on the ASU are seen during their admission by a member of the service. Ongoing work is then identified and prioritised according to overall service demand. A referral system still operates for patients on the HASU; however, a consultation session on the ward and attendance at the ward round is scheduled on a weekly basis to provide psychological management and consultation to the unit.

Data was collected prospectively using a standardised format on an Excel database by the Stroke Clinical Neuropsychology service. Data from March to October 2015, March-October 2016 and March-October 2017 were compared with a previous audit of the Stroke Clinical Neuropsychology service from November 2012 to June 2013. The number and type of patient contact were logged on this database for the purposes of analysis.

Data on the number of patients assessed for mood on admission is captured by The Sentinel Stroke National Audit Programme (SSNAP) (SSNAP is the single source of stroke data in England, Wales and Northern Ireland. It is a national clinical audit which monitors the quality of stroke services and improves services by highlighting to providers where they can improve.) and numbers from 2015 contributed to the analysis of the skill mix. Furthermore, in August 2015, a staff survey was conducted to obtain feedback from the MDT about the new Stroke Clinical Neuropsychology service. This survey was locally developed and distributed to all members of the MDT on the stroke unit. 
Stroke Clinical Neuropsychology service audit 2015 - total patients seen $2012 / 13$ vs 2015

194

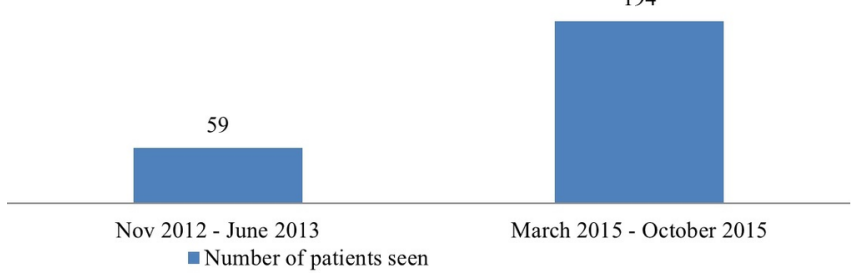

Figure 1 Total patients seen across both wards in 2012/2013 versus 2015 .

\section{RESULTS}

Clinical outcome-access to psychology

The service audit collated the number of individual patients seen, along with the type of psychological work delivered. Results are presented below.

In an 8-month period in 2012/2013, the service saw a total of 59 patients approximately of 800 admitted to Stroke Services in that period, so we can infer that just $7.4 \%$ of patients were seen by psychology in that year. Over a similar time frame in 2015, the service saw a total of 194 patients across both units, an increase of 228\% (see figure 1). The level of access was sustained in 2016 and 2017 with 185 and 135 patients being seen, respectively. The skill mix model has enabled $100 \%$ of patients to be seen by psychology since 2015 to date.

In the $2012 / 2013$ audit, $88 \%$ of patients seen by the service were on the ASU, $12 \%$ on the HASU. In the follow-up audit, $89 \%$ of patient seen by the service were on the ASU, $11 \%$ on the HASU (see figure 2).

The skill mix model was sustained and the increase in number of patients seen was maintained in 2016 with 178 seen in total across both units (172 in ASU, six in HASU) and 2017 (127 in ASU, eight in HASU).

Stroke Clinical Neuropsychology service audit 2015 - total patients seen 2012/13 vs 2015 by unit

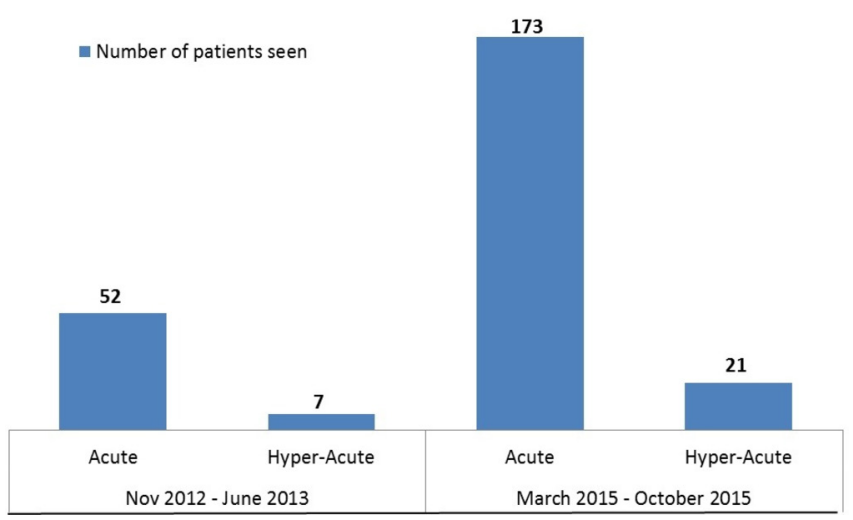

Figure 2 Breakdown of total patients by ward seen in 2012/2013 versus 2015 .

\section{Type of work 2012/13}

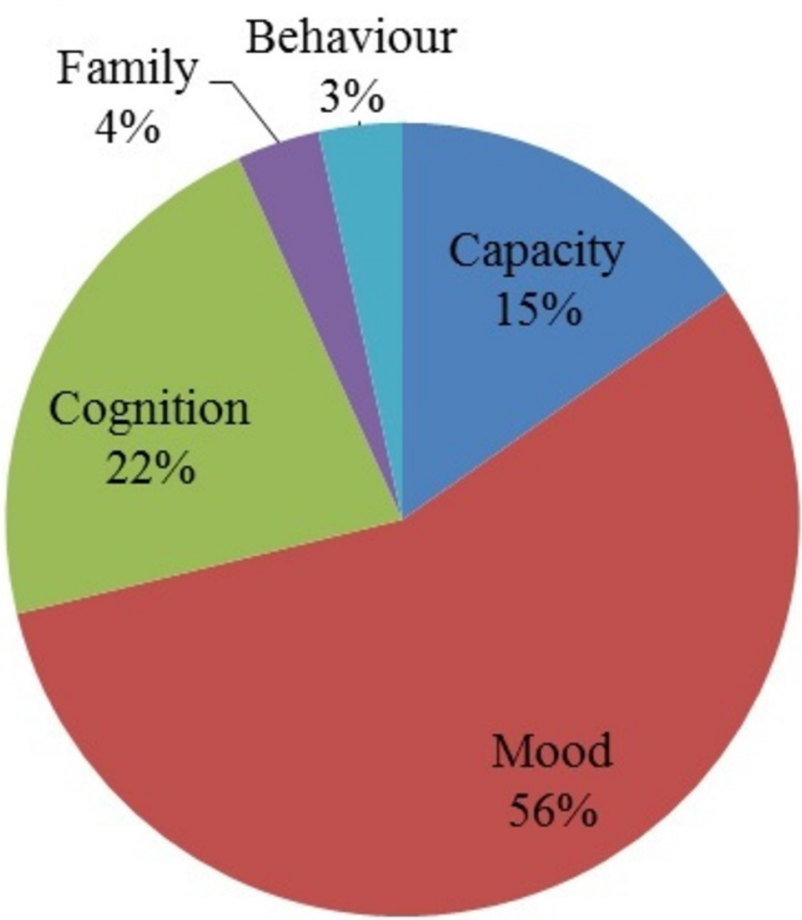

Figure 3 Type of interventions offered by the Stroke Clinical Neuropsychology service in 2012/2013 ( $n=59)$.

\section{Clinical outcome-access to a variety of treatments}

Figure 3 shows the breakdown of interventions offered by the Stroke Clinical Neuropsychology service in 2012/2013 to a total of 59 patients.

Figure 4 shows the breakdown of interventions offered by the Stroke Clinical Neuropsychology service in 2015 to a total of 133 patients.

In 2016 and 2017, the type of psychological work provided by the Stroke Clinical Neuropsychology service has remained broadly the same, the majority of work being for mood-related issues, followed by cognition and capacity. The skill mix model appears to allow for more family work, possibly due to the Band $7 \mathrm{~b} / 8 \mathrm{~b}$ being freed

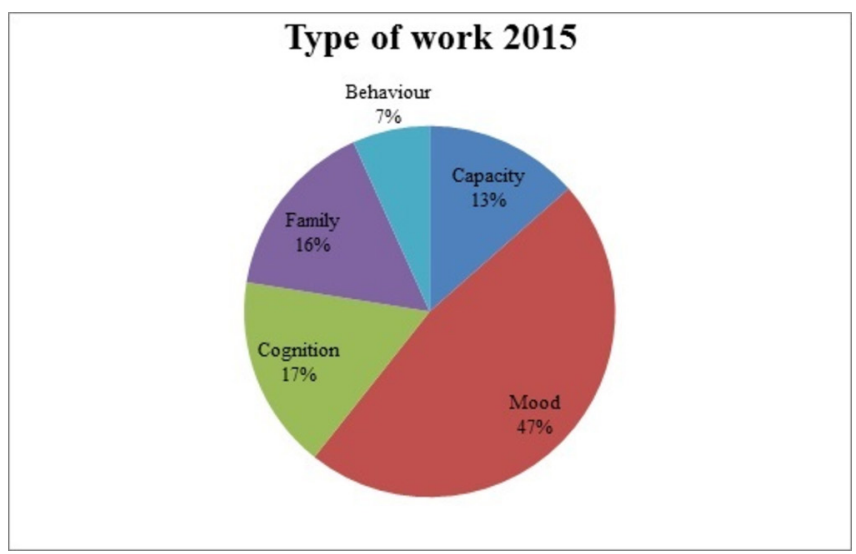

Figure 4 Type of interventions offered by the Stroke Clinical Neuropsychology service in $2015(n=133)$. 
Table 1 Summary of staff disciplines who completed the survey about accessibility and support

\begin{tabular}{lcc}
\hline Profession & $\mathbf{n}$ & \% \\
\hline Medical & 3 & 21 \\
Nursing & 8 & 58 \\
Therapies & 3 & 21 \\
Total & 14 & 100 \\
\hline
\end{tabular}

up to regularly attend family meetings, as well as liaise closely with families where required.

\section{Staff survey-increased MDT working}

A link to an online questionnaire was distributed to senior members of the MDT from all disciplines with a request to forward to all of their junior staff. The online questionnaire asked staff to rate how accessible they found the Stroke Clinical Neuropsychology service and how well supported they felt (on a five-point Likert scale). They were then asked for comments about what the service does well, what the service does not do so well and to make suggestions for improvement. The survey was completed by 14 members of the wider MDT: medical $(n=3)$, nursing $(n=8)$ and therapies $(n=3)$. The results are presented in tables $1-4$.

Out of 14 staff, 11 felt either mainly or very supported in their work by the stroke neuropsychology team. The results showed that 11 out of 14 staff who responded felt that the Stroke Clinical Neuropsychology service was either accessible or very accessible. Moreover, psychologists were present on the wards and embedded into the service, enabling increased MDT collaboration. Other comments within the categories above included 'good availability, rapid assessment where there are problems and routine assessments are completed, friendly, helpful, part of the team, clarity for cover at times of annual leave' and 'works as part of MDT, including all in discussions about patients'. There is a much more focused input and visibility by the team supporting patient care and ward staff since the changes were made in February 2015 'They are doing a good job keep up the good work and hopefully there (sic) post is permanent'.

\section{Areas for further improvements (one comment received)}

Accessibility of timely support, particularly on HyperAcute Stroke Unit, can be a problem-previously, when one psychologist present then handover of information was not an issue so it feels like it was easier to maintain a consistent dialogue about patient, service development project/multidisciplinary team process, etc.

At the time of publication, the 'skill mix' model was sustained as it appeared the model was working to maintain greater access to psychology and encourage MDT working.

\section{LESSONS AND LIMITATIONS}

This service audit has demonstrated that more patients have been seen in the service with the skill mix model than the previous model of provision. The implication of this is clearly that there is a higher likelihood of psychological problems being identified by the Stroke Clinical Neuropsychology service, and thus more timely interventions can be offered and psychological care needs reduced. This in turn may reduce the number of referrals by general practitioners to primary care services such as Improving Access to Psychological Therapies or indeed to specialist hospital services, for example, neuro outpatient where patients may be seen by a consultant, a nurse and a specialist neuropsychologist/clinical psychologist in order to have their needs addressed. Should such a model be adopted, it could serve to reduce the cost impact for those services on patients with long-term conditions such as stroke. In services where psychological resources are limited, clinical services may benefit from adopting a 'skill mix' model in order to maximise their resources while simultaneously meeting the varying needs of their patients. This model also allows the psychologists to identify and address psychological needs immediately rather than depend on a referral pathway, thereby eliminating a waiting list system. In doing so, it raises the value of psychological services in supporting treatment pathways. This is crucial as the NHS is currently in the context of efficiency savings while still maintaining good quality patient care. This current driver is due to the economic challenges posed by the UK recession which started in 2008. NHS funding is deemed by many to be commensurate with government cuts to the public purse. Therefore, in the current context of the UK economy, NHS cuts are inevitable. ${ }^{14}$ However, this model facilitates a broad, accessible psychology service, deliverable despite austerity imposed by funders. Further, the model allows psychologists to determine the true demand of the service they are working in (ie, what do they need to be doing?), rather than dealing solely with the current demand (eg, what is being referred to the service?).

Table 2 'How accessible are the psychologists for the Stroke wards?' Results from the survey

\begin{tabular}{|c|c|c|c|c|c|c|}
\hline & $\begin{array}{l}\text { Not accessible, it is } \\
\text { difficult to get hold } \\
\text { of them }\end{array}$ & $\begin{array}{l}\text { Not usually } \\
\text { accessible, but } \\
\text { at times I can get } \\
\text { hold of them }\end{array}$ & $\begin{array}{l}\text { Somewhat } \\
\text { accessible, I can } \\
\text { get hold of them } \\
\text { sometimes }\end{array}$ & $\begin{array}{l}\text { Accessible, I can } \\
\text { generally get hold of } \\
\text { them when I have an } \\
\text { inquiry }\end{array}$ & $\begin{array}{l}\text { Very accessible, } \\
\text { I can get hold of } \\
\text { them when I have an } \\
\text { inquiry }\end{array}$ & Total \\
\hline$\%$ & 7 & 0 & 14 & 58 & 21 & 100 \\
\hline
\end{tabular}


Table 3 'Do you feel supported in your work by the Stroke psychology team?' Results from the survey

\begin{tabular}{lllcccc} 
& $\begin{array}{l}\text { Very } \\
\text { unsupported }\end{array}$ & $\begin{array}{l}\text { Mainly } \\
\text { unsupported }\end{array}$ & $\begin{array}{l}\text { Somewhat } \\
\text { supported }\end{array}$ & $\begin{array}{l}\text { Mainly } \\
\text { supported }\end{array}$ & Very supported & Total \\
\hline No. of responses & 1 & 0 & 2 & 5 & 6 & 14 \\
$\%$ & 7 & 0 & 14 & 36 & 43 & 100 \\
\hline
\end{tabular}

Additionally, this study demonstrates the improved capability of the Stroke Clinical Neuropsychology service to interact with patients and families. Given the associated carer stress involved in caring for people following a stroke, ${ }^{34}$ earlier assessment and intervention with families will be of benefit to long-term recovery and ongoing support from family carers. Added to this, research suggests that increased education for patients and carers can reduce the longer term severity of emotional problems following stroke. ${ }^{15}$

The skill mix model has also proven to be popular among the wider MDT; there was one comment which stressed that timely support on the HASU could be improved. However, most staff reported that the psychologists are accessible and that they support the MDT in their work. A variety of reasons may be responsible for this; however, it was clear from the results that most staff felt supported in their role and that psychologists were accessible and available for consultation. Previous research has demonstrated that effective MDT working should encourage communication and cooperation between MDT members. ${ }^{16}$ This is reflected in staff views of the skill mix model of clinical neuropsychology provision to patients with stroke. However, the survey is limited to only 14 members of staff completing it. Although the qualitative feedback was largely positive, areas of improvement for the service were identified by some MDT members. The issue of continuity of staff was highlighted by one individual as a problem on the HASU. With a skill mixed service, consisting of different grade staff working across the HASU and ASU, this feedback was to be anticipated. MDT staff had been used to seeing only one psychologist previously, but following implementation of the skill mix model, they were likely to see one of several staff members across a working week. Within the Stroke Clinical Neuropsychology service, communication between staff members about patients was identified as a potential risk to the model of working and a shared database was established for all psychology team members to use in order to provide seamless information about each patient seen by the service.

Table 4 'What does the team do well?' Results from thematic analysis

\begin{tabular}{llc}
\hline Theme & Mentions & N \\
\hline Multidisciplinary team working & IIIIIIIII & 10 \\
Service model & IIIIIIII & 9 \\
Behaviour work & IIII & 4 \\
\hline
\end{tabular}

\section{Limitations}

This study was limited by being a single site study; it is possible that variations in services delivered may have been seen if there were multiple sites. Neuropsychology services for patients following discharge are often not consistent across different geographical areas. Furthermore, there was no resource available to ascertain whether psychology recommendations made by the Stroke Clinical Neuropsychology service were routinely followed up after discharge. The data was self-collected and not verified by an independent rater which may have biased the results. Additionally, it was a small survey size. It is also worth considering that a substantial proportion of the Stroke Clinical Neuropsychology service's work was related to mood issues; it would therefore be logical to follow-up this study with examination of the efficacy of specific interventions offered to stroke patients in the hyper-acute and acute phases of their treatment (eg, behavioural activation, cognitive behavioural therapy).

However, the project demonstrated that substantially more inpatients would be seen by psychologists following a stroke with a skill mix model in place.

\section{CONCLUSIONS}

Regular assessment and management of mood problems following a stroke is core clinical neuropsychology work within a Stroke Service and is recommended by both RCP and NICE. ${ }^{25}$ This current service audit compared two different models of providing such a service within a London hospital with both HASU and ASU.

The higher number of patients assessed using the 2015 skill mix model of service provision suggests that more patients will have psychological needs identified and met during their inpatient stay. This will benefit patients, both in the short and longer term recovery from stroke, but also is likely to support staff MDT's working on Stroke Units thus ensuring compliance with both of these important national guidelines.

This study also demonstrates the improved capability of the Stroke Clinical Neuropsychology service to provide support to family/carers and may reduce the longer term severity of emotional problems following stroke by facilitating stroke education. ${ }^{14}$

In conclusion, this paper has demonstrated that service redesign using a skill mix model can improve service delivery and efficiency, support for families/carers and MDT working. 
Acknowledgements Acknowledgements are extended to SB, who supported and supervised NTB in implementing the skill mix model; the psychology team of the Stroke Clinical Neuropsychology service, for the support in transiting to the skill mix model; the MDT of the Stroke Clinical Neuropsychology service, who participated in the staff survey and to Richard Scott, AP, GC and MAS, who contributed to the write up of this article.

Contributors The authors listed contributed to the writing of this article for submission. NTB is the main contributor for this manuscript, taking care of the write up, design of the study, execution, data analysis and dissemination. RS contributed to the data analysis and write up. AP contributed to the write up. GC and MAS contributed to the editing. SB supervised NB and was a visionary for the quality improvement project.

Funding Data was collected as part of the normal day to day running of the NHS Stroke Clinical Neuropsychology service. No specific funding was required. Competing interests None declared.

Patient consent for publication Not required.

Provenance and peer review Not commissioned; externally peer reviewed.

Open access This is an open access article distributed in accordance with the Creative Commons Attribution Non Commercial (CC BY-NC 4.0) license, which permits others to distribute, remix, adapt, build upon this work non-commercially, and license their derivative works on different terms, provided the original work is properly cited, appropriate credit is given, any changes made indicated, and the use is non-commercial. See: http://creativecommons.org/licenses/by-nc/4.0/.

\section{REFERENCES}

1. Hackett ML, Anderson CS, House A, et al. Interventions for preventing depression after stroke. Cochrane Database Syst Rev 2008;16:CD003689.

2. National Institute for Health and Care Excellence (NICE; 2010). Stroke in adults: quality standard: National Institute for Health and Care Excellence publications.
3. Mackenzie A, Perry L, Lockhart E, et al. Family carers of stroke survivors: needs, knowledge, satisfaction and competence in caring. Disabil Rehabil 2007;29:111-21.

4. Simon C, Kumar S, Kendrick T. Formal support of stroke survivors and their informal carers in the community: a cohort study. Health Soc Care Community 2008;16:582-92.

5. Royal College of Physicians (RCP; 2016). National clinical guidelines for stroke. 5th edn: Royal College of Physicians online publications, 2016.

6. Lincoln NB, Kneebone II M, Morris RC. Neuropsychological assessment after stroke: John Wiley \& Sons, Ltd, 2012.

7. Hackett ML, Yapa C, Parag V, et al. Frequency of depression after stroke: a systematic review of observational studies. Stroke 2005;36:1330-40.

8. Stroke Association. State of the nation: stroke statistics: Stroke Association online publications, 2016.

9. National Audit Office (NAO; 2010). Progress in improving stroke care: Department of Health publications, 2010.

10. Gibbon B, Little V. Improving stroke care through action research. J Clin Nurs 1995;4:93-100.

11. Improvement Stroke NHS. Psychological care after stroke: improving stroke services for people with cognitive and mood disorders: NHS online publications, 2011.

12. Nys GM, van Zandvoort MJ, de Kort PL, et al. Cognitive disorders in acute stroke: prevalence and clinical determinants. Cerebrovasc Dis 2007;23:408-16.

13. Leśniak M, Bak T, Czepiel W, et al. Frequency and prognostic value of cognitive disorders in stroke patients. Dement Geriatr Cogn Disord 2008;26:356-63.

14. England NHS. Implementing the five year forward view for mental health. London: NHS England, 2016.

15. Forster A, Brown L, Smith J, et al. Information provision for stroke patients and their caregivers. Cochrane Database Syst Rev 2012;11:CD001919.

16. Landry A, Erwin C. Perspectives on multidisciplinary team processes among healthcare executives: processes that facilitate team effectiveness. J Health Hum Serv Adm 2015;38:350-80. 